\title{
Immature sound localisation and abnormal development
}

\author{
M JAFFE, E TIROSH, D ORIAN, AND R SHENHAVE \\ Paediatric Department, Hannah Khoushy Child Dêvelopment Centre, Haifa Medical Centre (Rothschild), \\ Institute for Hearing and Speech Disorders, Rambam Medical Center, and Faculty of Medicine, \\ Technion-Israel Institute of Technology, Haifa, Israel
}

SUMMARY This investigation tested the hypothesis that high risk infants showing immaturity in localisation of a sound stimulus would be more likely to have appreciable neurodevelopmental dysfunction. The cohort comprised 112 infants, 66 of whom were classified as 'high risk'. Every infant underwent a neurological and developmental assessment, a sound localisation response test, and an audiological examination when necessary. The first examination was performed at age 8-9 months and was repeated between six and eight months later. It was found that if the sound localisation response was mature at the first examination normal development could be anticipated at the second examination. If an immature sound localisation response was shown then considerable dysfunction could be anticipated in about half of the infants. It is suggested that special attention be paid to the maturity of the sound localisation response in infants during auditory screening procedures, and an immature response should alert the examiner to the possibility of appreciable abnormality in development.

Preterm infants often show developmental delay or dysfunction during early life. Many of these infants have normal potential and will subsequently catch up their peers. A proportion, however, remain delayed and will later manifest signs of mental retardation or cerebral palsy, or both. ${ }^{1}$ With the advent of sophisticated, modern techniques of perinatal care, many more preterm infants are being saved, and the clinician is faced with the dilemma of diagnosing important psychomotor development problems requiring early intervention. ${ }^{2}$ Any procedure that might aid the correct early identification of these high risk infants would therefore be of considerable value.

The sound localisation response seemed an appropriate area of investigation when a number of infants were referred to our child development centre by an audiologist with the comment that the infants' hearing was normal but that their ability to localise the source of a sound stimulus was not appropriate for their age. On developmental assessment a high proportion of these infants were found to have important neurodevelopmental dysfunction requiring intervention.

Various authors have described a developmental sequence of auditory localisation. ${ }^{34}$ On this basis, a study was planned wherein a mixed sample of infants, comprising a high risk group and a low risk group, underwent a test for sound localisation response. The results were correlated with their developmental attainments at that time and six months later. It was hypothesised that those infants who showed an immature sound localising response would be more likely to have appreciable abnormal development subsequently.

\section{Patients and methods}

One hundred and twenty two infants between the ages of 8 and 9 months, attending well baby clinics, were selected by a clinic nurse (who was not participating in the study and was not aware of the developmental state of the infants). Of these, 66 were classified as high risk by virtue of having been exposed to gestational or perinatal events known to be potentially damaging to the central nervous system (Table 1). The remaining 56 infants, who had not been subjected to known risk factors, comprised the low risk group. The two groups were similar with regard to ethnic origin and socioeconomic state of the father. The examiners participating in the study were unaware of the classification of the infants. 
Table 1 Distribution of risk factors among the high risk group

\begin{tabular}{|c|c|c|c|}
\hline & \multirow{2}{*}{$\begin{array}{l}\text { Full term } \\
\text { infants } \\
(n=15)\end{array}$} & \multicolumn{2}{|c|}{ Premature infants } \\
\hline & & $\begin{array}{l}>1500 \mathrm{~g} \\
(n=43)\end{array}$ & $\begin{array}{l}<1500 \mathrm{~g} \\
(n=4)\end{array}$ \\
\hline Fetal distress & 4 & 2 & \\
\hline Meconium aspiration & 2 & & \\
\hline Asphyxia & 8 & 7 & 2 \\
\hline Small for dates & 6 & 8 & \\
\hline Respiratory distress syndrome & 2 & 14 & 3 \\
\hline Jaundice & & 18 & 3 \\
\hline Apnoeic episodes & & 7 & 1 \\
\hline Patent ductus arteriosus & & 3 & 1 \\
\hline Hypoglycaemia & 2 & 17 & \\
\hline Convulsion & & 2 & \\
\hline Sepsis & 2 & 2 & 1 \\
\hline
\end{tabular}

The developmental assessment of the preterm infants was corrected for gestational age. The study was divided into two stages, initial examination and follow up.

Initial examination comprised the Bayley scale of infant development, ${ }^{5}$ including mental developmental index and psychomotor developmental index, the Stycar hearing screening test, ${ }^{6}$ and sound localisation response test. ${ }^{3}$ The mental and psychomotor developmental indexes provide an objective assessment of mental and psychomotor development and have a low degree of observer bias; they were reported separately to provide a more reliable profile of developmental skills.

In the hearing tests the infant was placed on the mother's lap opposite an observer. The examiner, stationed one metre from the infant and outside his range of peripheral vision, produced sound stimuli of various frequencies, at and $45^{\circ}$ below and above ear level. The infant's response was recorded as normal if, at 8 months, he was able to look directly at the sound source below ear level or in an arc when the stimulus was above ear level.

Any infant who showed an immature sound localisation response was referred for complete audiologic evaluation, including brain evoked response audiometry.

The cohort was re-examined between six and eight months later. All babies again underwent the Bayley developmental assessment $t^{5}$ as well as complete physical and neurological examination.

Any health or developmental problems occurring over this period were treated according to the routine procedure operative at the time in the clinic.

\section{Results}

Of the 122 originally recruited subjects, $112(92 \%)$ completed the study. Of the 10 who dropped out of the study, four belonged to the high risk and six to the low risk group (Table 2). They all failed to complete the second stage of the study. The sound localisation response was normal in all 10 of these children, and their developmental quotient was similar to the cohort group.

An immature sound localisation response was shown by 12 infants, $10(16 \%)$ of whom were from the high risk and two (4\%) from the low risk group. This figure was significant only at the level of $p<0 \cdot 1$ (by $\chi^{2}$ analysis) but probably indicates a trend.

Significantly lower mental and psychomotor developmental indexes were found in subjects with an immature response when compared with those with a mature response. These differences were already evident at the age of 8-9 months and became more pronounced by the age of 14-15 months (Table 3 ).

In Tables 4 and 5 the scores of the mental and psychomotor developmental indexes of the total cohort are analysed with reference to the type of sound localisation response. Mean scores for the low risk group minus 2 standard deviations were used as the cut off point for normal developmental performance (mental and psychomotor developmental indexes $<76$ and $<73 \cdot 5$, respectively). This analysis showed a significantly lower performance in the

Table 2 Cohort tested for sound localisation response

\begin{tabular}{|c|c|c|c|}
\hline & \multicolumn{2}{|l|}{ Group } & \multirow{2}{*}{$\begin{array}{l}\text { Total } \\
\text { cohort } \\
(n=122)\end{array}$} \\
\hline & $\begin{array}{l}\text { High risk } \\
(n=66)\end{array}$ & $\begin{array}{l}\text { Low risk } \\
(n=56)\end{array}$ & \\
\hline $\operatorname{Sex}(M: F)$ & $37: 29$ & $33: 23$ & $70: 52$ \\
\hline \multicolumn{4}{|l|}{ Initial examination (months/days): } \\
\hline Age range & $7 / 5-10 / 14$ & $7 / 15-10 / 19$ & \\
\hline Mcan age & $8 / 21$ & $8 / 21$ & $8 / 21$ \\
\hline \multicolumn{4}{|l|}{ Follow up examination (months/days): } \\
\hline Age range & $13 /(0-18 / 17$ & $13 / 4-18 / 11$ & \\
\hline Mean age & $15 / 10$ & $15 / 26$ & $15 / 18$ \\
\hline Dropouts & 4 & 6 & 10 \\
\hline Completed study (No (\%)) & $62(94)$ & $50(89)$ & $112(91)$ \\
\hline $\begin{array}{l}\text { Mature:immature sound localisation } \\
\text { response }(\mathrm{No}(\%))\end{array}$ & $52: 10(16)$ & $54: 2(4)$ & $106: 12(11)$ \\
\hline
\end{tabular}

Table 3 Relation between developmental quotient (mean (SD)) and maturity of sound localisation response

\begin{tabular}{|c|c|c|c|c|}
\hline \multirow{2}{*}{$\begin{array}{l}\text { Developmental } \\
\text { index }\end{array}$} & \multicolumn{2}{|c|}{ Sound localisation response } & \multirow[t]{2}{*}{ t Value } & \multirow[t]{2}{*}{ p Value } \\
\hline & Immature & Mature & & \\
\hline \multicolumn{5}{|l|}{ At 9 months: } \\
\hline Mental & $84 \cdot 2(26 \cdot 0)$ & $101 \cdot 7(12 \cdot 6)$ & $3 \cdot 743$ & $<0 \cdot(000) 5$ \\
\hline Psychomotor & $66.5(16.9)$ & $89 \cdot 0(14 \cdot 8)$ & 4.980 & $<0 \cdot(x)(05$ \\
\hline \multicolumn{5}{|l|}{ At 15 months: } \\
\hline Mental & $72 \cdot 4(20 \cdot 4)$ & $99 \cdot 1(11 \cdot 8)$ & $6 \cdot 605$ & $<0 \cdot(0005$ \\
\hline Psychomotor & $68 \cdot 2(14 \cdot 0)$ & $94 \cdot 1(12 \cdot 6)$ & 6.559 & $<0 \cdot(0005$ \\
\hline
\end{tabular}


group with an immature response. The sensitivity for the mental and psychomotor developmental indexes was $58 \%$ and $50 \%$, respectively, while the specificity was $95 \%$ and $94 \%$, respectively. Positive predictive value was $58 \%$ and $50 \%$ and negative predictive value $95 \%$ and $94 \%$, respectively. Total accuracy was $90 \%$.

Ten of the 12 infants in the group with an immature response were premature and suffered from additional risk factors. No specific combination of potentially damaging events could be implicated (Table 1). No hearing defect was found in the infants with an immature sound localisation response.

Table 6 shows that, irrespective of risk category, it was in fact the maturity of the sound localisation response that was associated with the performance

Table 4 Screening value of sound localisation response test for mental developmental index

\begin{tabular}{|c|c|c|c|}
\hline \multirow{2}{*}{$\begin{array}{l}\text { Sound } \\
\text { localisation } \\
\text { response }\end{array}$} & \multicolumn{2}{|c|}{ Developmental quotient } & \multirow[t]{2}{*}{ Total } \\
\hline & $<76$ & $>76$ & \\
\hline Immature & 7 & 5 & 12 \\
\hline Mature & 5 & 95 & 100 \\
\hline Total & 12 & 100 & 112 \\
\hline
\end{tabular}

Sensitivity $58 \%$; specificity $95 \%$; positive predictive value $58 \%$; negative predictive value $95 \%$; total accuracy $\left.91 \% ; \chi^{2}=26 \cdot 5() ; p<0\right) \cdot(0)(05$

Table 5 Screening value of sound localisation response test for psychomotor developmental index

\begin{tabular}{llcc}
\hline $\begin{array}{l}\text { Sound } \\
\text { localisation } \\
\text { response }\end{array}$ & \multicolumn{2}{c}{ Developmental quotient } & Total \\
\cline { 2 - 3 } & $<73 \cdot 4$ & $>73 \cdot 4$ & \\
\hline $\begin{array}{llcr}\text { Immature } \\
\text { Mature }\end{array}$ & 6 & 6 & 12 \\
\hline Total & 6 & 94 & 100 \\
\hline
\end{tabular}

Sensitivity $50 \%$; specificity $94 \%$; positive predictive value $50 \%$ : negative predictive value $94 \%$; total accuracy $89 \%: \chi^{2}=17 \cdot 32 ; p<0 \cdot(k) 5$. on the Bayley test. Despite the difference in the score of psychomotor developmental index $(p<0.05)$ between those with a mature response in favour of the low risk group, when maturity of the sound localisation response was considered this disparity became much more significant $(\mathrm{p}<0 \cdot 0005)$.

\section{Discussion}

Auditory screening programmes in infancy are being used increasingly for the early detection of hearing defects in infants. The purpose of this study was to determine whether the incorporation of an assessment of the infant's ability to localise a sound source might provide information on his neurodevelopmental state.

In an attempt to address this question a simply performed assessment of the infant's ability to localise the origin of a sound source was evaluated by comparing the maturity of the response of his developmental performance at the time and again six to eight months later. While other studies have shown an association between an immature sound localisation response and subsequent language delay at age 36 months, ${ }^{78}$ our study showed the correlation between sound localisation response and subsequent development at an earlier age.

Analysis of the validity of the sound localisation response indicated that if this was mature at the age of 8-9 months then the clinician could reliably predict normal development six months later. An immature response, however, was associated with significantly delayed mental and psychomotor developmental indexes in $58 \%$ and $56 \%$ of subjects, respectively, thus yielding a large number of false positives.

Our study group comprised $54 \%$ high risk infants. This might resemble the situation seen in neonatal special care follow up clinics, and the positive predictive value of the sound localisation response test would therefore be similar to our findings. The well baby clinic population is, however, a different one, and it might be assumed that the pretest

Table 6 Analysis of the relation between maturity of sound localisation response, developmental quotient, and risk category. Values are mean $(S D)$

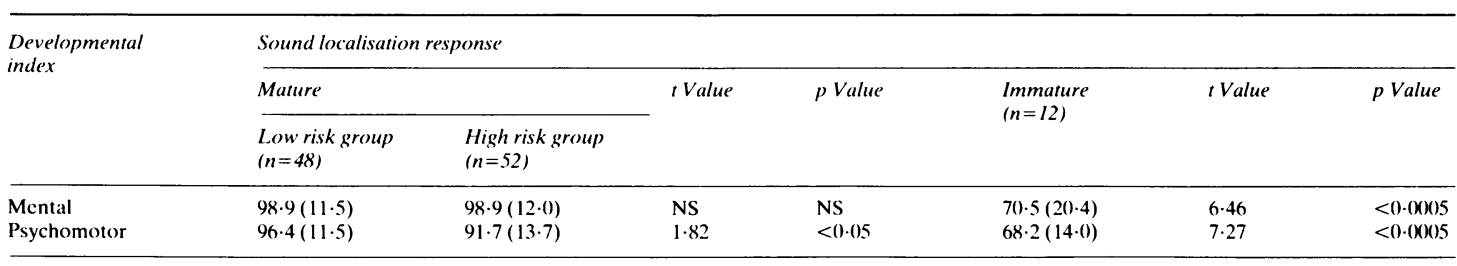

NS $=$ not significant 
likelihood of developmental delay would be $\pm 5 \%$. The positive predictive value would, therefore, decrease to $38 \%$ and the negative predictive value would increase to $98 \%$. Even in this situation it is evident that the sound localisation response test would be of definite value to the clinician.

We therefore confirm that the sound localisation response can be of value in providing information on the developmental state of the infant. The procedure is easy to learn and takes no longer than three to four minutes to perform. We recommend that it be incorporated into routine infant follow up examinations as well as any screening programmes. Medical or paramedical staff should also find this developmental milestone useful in evaluating infants, especially high risk premature infants or those with questionable development, a normal sound localisation response being associated with a favourable outlook. It is to be emphasised that evaluation of the sound localisation response is not a short cut to providing a developmental diagnosis but can help in the early selection of those infants at greater risk for appreciable neurodevelopmental dysfunction.

\section{References}

${ }^{1}$ Saigal S, Rosenbaum P, Staskopf B, et al. Follow-up of infants of 501-1500g birth weight delivered to residents of a geographically defined region with perinatal intensive-care facilities. $J$ Pediatr 1982;100:606-13.

2 Simeonsson RI, Cooper HH, Scheiner AP. A review and analysis of the effectiveness of early intervention programs. Pediatrics 1982;69:635-41.

${ }^{3}$ Murphy KD. Reactions of infants to sound. In: Fisch L, ed. Research in deafness in children. Oxford: Blackwell, 1962.

${ }^{4}$ Downs MP, Silver HK. The "A.B.C.D's to H.E.A.R." early identification in nursery, office, and clinic of the infant who is deaf. Clin Pediatr (Phila) 1972;11:563-6.

5 Bayley N. Bayley scales of infant development. New York: Psychological Corporation, 1969.

6 Sheridan MD. Manuals of instruction for Stycar tests of vision, hearing, and language. Windsor: NFER Publishing, 1968.

${ }^{7}$ Lassman FM, Fisch RO, Vetter PK, LaBerg ES. Early correlation of speech, language and hearing. Littleton, Massachusetts: PSG Publishing Company, 1980.

${ }^{8}$ Swift EW, Swift WJ, Camp BW, Silvern LW. Predictive value of early testing of auditory localization for language development. Dev Med Child Neurol 1981; 23:306-12.

Correspondence to Dr M Jaffe, Paediatric Department, Haifa Medical Center, P O B 4940, Haifa 31048, Israel.

Received 20 May 1986 